\title{
What Can Be Done to Change?-The Environmental and Behavioral Consequences of Interventions for Sustainable Travel
}

\author{
Lars E. Olsson ${ }^{1, * \mathbb{C}}$, Rajib Sinha ${ }^{2} \mathbb{D}$, Björn Frostell ${ }^{3}$ and Margareta Friman ${ }^{1} \mathbb{D}$ \\ 1 CTF Service Research Center and Department of Social and Psychological Studies, Karlstad University, \\ SE-651 88 Karlstad, Sweden; Margareta.Friman@kau.se \\ 2 Department of Sustainable Development, Environmental Science and Engineering (SEED), School of \\ Architecture and the Built Environment, KTH Royal Institute of Technology Stockholm, Teknikringen 10B, \\ 10044 Stockholm, Sweden; rajibs@kth.se \\ 3 Ecoloop AB, 11646 Stockholm, Sweden; bjorn.frostell@ecoloop.se \\ * Correspondence: lars.e.olsson@kau.se; Tel.: +46-54-700-2498
}

Citation: Olsson, L.E.; Sinha, R.; Frostell, B.; Friman, M. What Can Be Done to Change?-The Environmental and Behavioral Consequences of Interventions for Sustainable Travel. Sustainability 2022, 14, 1345. https://doi.org/ $10.3390 /$ su14031345

Academic Editor: Marc A. Rosen

Received: 21 January 2022

Accepted: 23 January 2022

Published: 25 January 2022

Publisher's Note: MDPI stays neutral with regard to jurisdictional claims in published maps and institutional affiliations.

Copyright: (c) 2022 by the authors. Licensee MDPI, Basel, Switzerland. This article is an open access article distributed under the terms and conditions of the Creative Commons Attribution (CC BY) license (https:// creativecommons.org/licenses/by/ $4.0 /)$.

\section{Introduction}

We organized this Special Issue on "The Environmental and Behavioral Consequences of Interventions for Sustainable Travel" with the aim of attracting interdisciplinary perspectives on the environmental and behavioral consequences of different interventions for sustainable travel. In doing so, we brought together researchers from a variety of academic backgrounds who provide meta-analyses, conceptual models, and empirical studies that give us a broad understanding of the links between travel behavior and sustainability, as well as different evaluations and measures for assessing the impact and consequences of travel behavior interventions.

Transport is at the crossroads in the climate and sustainable development discussion. In the UN's Sustainable Development Goals [1], it appears as an important component of goal 7 (Assure access to affordable, reliable, sustainable and modern energy for all), goal 8 (Promote sustained, inclusive and sustainable economic growth, full and productive employment and decent work for all) and goal 9 (Build resilient infrastructure, promote inclusive and sustainable industrialization and foster innovation). These three goals are predominantly growth-oriented rather than governance-oriented (cf. UN Sustainability Goals [1]). The European Union has adopted a strategy for sustainable mobility whose main target is working toward mobility solutions that are sustainable, energy-efficient and respectful to the environment [2]. In this, technical innovations and alternative fuels make up one part that will contribute toward achieving the target. Sustainable transportation, however, is also a target of goal 11 (Make cities and human settlements inclusive, safe, resilient and sustainable), placing the individual front and center. Thus, in addition to new technical developments, the subjective dimensions of individual perceptions, experiences and behaviors should also be considered.

This Special Issue focuses specifically on personal travel. Personal travel includes many different components, e.g., various transport services, individual demand, movements, experiences, and pollution. The contributions made to this Special Issue only cover a fraction of what is generally included in the definition of sustainable travel [2]. With the aim of visualizing how the 9 contributions made to this Special Issue fit into an overall transport perspective, we have devised a "transport tree" (Figure 1). A conclusion here is that the topic of our Special Issue covers local/regional personal travel, predominantly work and business travel. As our contributions only relate to a minor part of sustainable transport, it is important to remember how large and complex the issue is, even though it is only a minor part of the overall sustainability challenge. Importantly, however, this Special 
Issue covers areas where individuals have the possibility themselves of making responsible choices, thus contributing toward sustainable development.

\section{A transport tree}

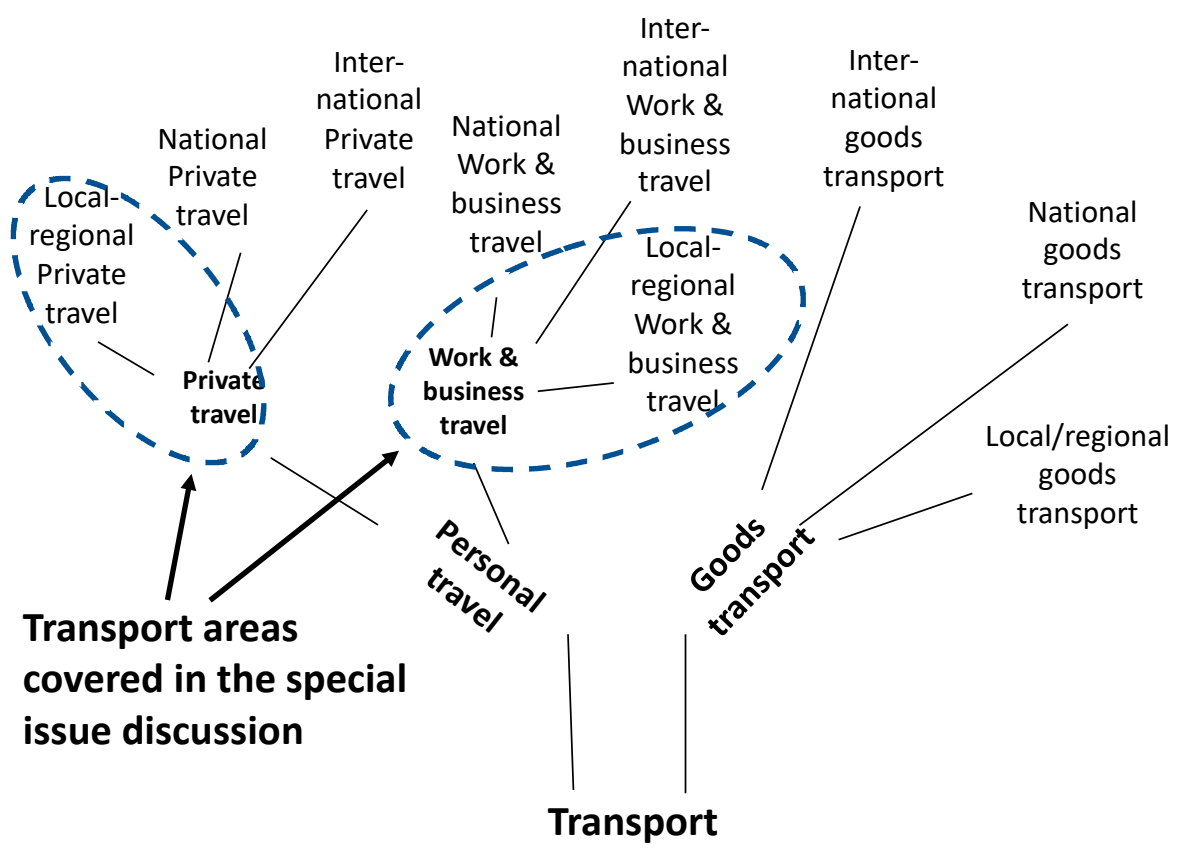

Figure 1. A transport tree visualizing the contributions made to this Special Issue.

Nine papers, with authors and cases primarily from Europe, but also from the US, China and South Africa, have contributed knowledge, covering areas as diverse as carpooling, cycling, bike-sharing and E-bike interventions, visual impairments, mobile phone applications, mobility culture, public transport use, and environmental modelling. A plethora of methods has been applied, including qualitative, quantitative, and mixedmethod approaches, in addition to meta-analysis and life-cycle modelling. Broadly speaking, the papers (listed in part 4) can be categorized into four themes: Understanding car-users, Mobile phone applications for sustainable travel, Interventions for active travel, and Environmental footprints of daily travel.

Next, we summarize the nine contributions divided between the four identified themes (part 2). This is followed by a general discussion on the theme of this Special Issue, the identification of missing pieces, and reflections on avenues for future research (part 3 ).

\section{Summary of the Contributions}

\subsection{Understanding Car-Users}

In the first contribution, Olsson et al. (Contribution 1) argues that carpooling can be viewed as a simple intervention for reducing problems related to congestion, the environment, and land use. There is, however, a need to better understand why and when people adopt carpooling as their means of travel. Specifically, their aim was to understand user characteristics, motives, and barriers to carpooling, and to determine the effects of interventions for carpooling. In their efforts to provide this knowledge, Olsson et al. conducted a meta-analysis of recently published (2014-2018) worldwide research on carpooling. Among 18 published papers, 20 different factors were identified for which effect sizes were calculated. Based on these effect sizes, the authors state that carpooling is only very weakly related to socio-demographics, and that psychological factors are becoming more important, including perceptions regarding money and time, congestion, and environmental concerns. As expected, fuel price is also an important factor of influence. Some policy-based interventions may increase carpooling, such as cheaper or dedicated parking 
spaces for carpoolers, and the commissioning of high-occupancy vehicle (HOV) lanes. The meta-analysis supports earlier research but adds the insight that judgmental factors have become more important for choosing to carpool. These researchers conclude that carpooling fails to attract many potential users as it currently does not serve these users adequately, and they propose that, to meet the challenge of the diverse needs of potential users, new forms of carpooling concepts, systems, and services may be needed.

Bergman (Contribution 3) aims to understand the links between agency and (un)sustainable travel in a US American mobility culture. In her paper, entitled "Trains in the Land of the Car: A Case Study of Mobility as Agency in the United States", she applies Bandura's three modes of agency, whereby individual agency relates to processes where individuals guide their own behavior to achieve their goals, where proxy agency is when someone else helps out in achieving our goals by acting on our behalf, and where collective agency is when people work together to achieve their goals through interdependent efforts. With the aim of investigating how US car users make sense of their mobility practices in relation to trains, Bergman interviewed 32 car-users from regions which no longer have an adequate train infrastructure. Based on content analysis, a mixed-method analytic framework, and using multidimensional scaling, Bergman's findings reveal that Bandura's ideas regarding individual and proxy agency define the mobility practices of the interviewees. Interestingly, collective agency, as proposed by theory, is largely absent among US car users. The respondents' addiction to comfort and convenience and their imagined sense of freedom are interpreted as an obstacle to their ability to envisage sustainable lifestyles and consumption. It is concluded that, regardless of the respondents' ideas regarding current and future travel, the actual absence of sustainable alternatives, the lack of political willpower to bring about change, and the existence of institutionalized norms and values are all strong barriers to overcome.

\subsection{Mobile Phone Applications for Sustainable Travel}

In this second theme, two papers specifically address the issue of whether mobile phone applications can be used as an aid for encouraging people to reduce their car use and make sustainable mobility choices, which result in a lower environmental footprint. In one of the papers, Cellina et al. (Contribution 2) designed GoEco!; a smartphone application that uses automatic mobility tracking, eco-feedback, social comparison and gamification elements in order to encourage sustainable mode choices. GoEco! is anchored in the Transtheoretical model for behavior change (see, for example, Contribution 1 and [3]), according to which change occurs by means of several motivational processes that make individuals progress from being less to more motivated to change or, as the theory states: to change from the stage of pre-contemplating change to the stage of maintaining new and healthy or sustainable behavior. In line with theory, GoEco! was endowed with a set of features and components specifically designed to support individuals at each stage of their behavior change. During a one-year large-scale, randomized and controlled trial, Cellina et al. introduced GoEco! in two regions of Switzerland. Practical difficulties in performing this randomized and controlled trial were encountered, with large drop-out rates throughout the experiment, leading to a very small sample to make inferences from. However, a statistically significant impact was observed, including a decrease in $\mathrm{CO}_{2}$ emissions and energy consumption per kilometer travelled. The observations were only found, however, in systematic routes in highly car-dependent urban areas, and not in areas where high-quality public transport was already in place. The authors propose that GoEco!-like persuasive apps could effectively complement new infrastructural measures aimed at promoting active travel for public health reasons by providing personalized recommendations, challenges and badges directed at healthy and sustainable routes and modes.

Andersson et al. (Contribution 5) tested a mobility service application for business travel. This application was introduced in 13 Swedish organizations to facilitate the booking and management of business trips, with a special emphasis on public transportation. A 
before-and-after study was employed featuring surveys and interviews with employees of these organizations. The results showed that the application was primarily used for regional and local public transport trips, a finding also emphasized by the respondents themselves, indicating that the application made it easier to travel by public transport. The authors reflectively attach caveats to these findings due to the small sample size. During follow-up interviews with employees, three factors were identified as relevant to increasing sustainable business trips: management control and proactiveness; perceived improvement of interventions; functions and technical sufficiency. Andersson et al. conclude that organizational conditions facilitating sustainable business travel, including coherent travel policy, accessibility to sustainable modes of transport, and a culture that encourages environmentally friendly behavior, may be important foundations to build upon.

\subsection{Interventions for Active Travel}

This third theme consists of empirical studies focusing on different forms of interventions related to active travel. By active travel, we mean here cycling, e-bikes and walking. The first paper was written by Dahl Wikstrøm and Böcker (Contribution 9). Theoretically, these scholars build upon the staging mobilities framework, involving the dimensions of embodiment, social interaction, and materiality. Qualitatively, these authors explore the potential of combining mobile methods, e.g., GPS-tracking, qualitative GIS, participant observations, and visual methods such as photos taken by participants in combination with map-elicitation during interviews. Dahl Wikstrøm and Böcker present an e-bike intervention regarding suburban commuters in Norway wherein they explore how local mobility interventions can assist changes to daily mobilities. The empirical material is claimed to provide promising evidence that e-bikes can play a crucial role in the transition to sustainable transportation. There is an elaboration upon how a new e-bike practice like this is, and can be, intertwined with existing daily activities and mobility systems. Based on their findings, the authors argue that transport interventions introducing active transport modes, e.g., e-bikes, can have a significant impact on reducing emissions from suburban commutes and mobility; insights that contribute to the reframing of the idea that suburban environments and mobility are car-dependent.

Blitz et al. (Contribution 6) conducted their study of 'Cycle streets', which are shared streets where the entire roadway is dedicated to cyclists, with motorized traffic being subordinate. The idea behind these cycle streets is enriching sustainable travel by giving urban space back to active travel. However, evidence of the impact of cycle street interventions relating to travel behavior change is scarce. In this study, a written household survey was completed by participants affected by a cycle street intervention in the German city of Offenbach am Main $(n=701)$. In line with Cellina et al. (Contribution 2), Blitz et al. also take their theoretical stance in stage-based models of motivation; specifically, a two-stage model of self-regulated behavioral change. In doing so, they have identified the participants' level of motivation to both use a bicycle and reduce their car use. The findings showed that the cycle street had a positive impact on frequent bicycle use, but only a minor effect on the reduction of car-use. Furthermore, they also identified traffic conflicts and vehicle speeding on the cycle street as being a major negative influence on the acceptance of the intervention. As regards the stage-based motivation, it was observed that awareness and regular use of the cycle street intervention were linked to the transition to a higher motivational stage, thus potentially relating positively to maintaining regular bicycle use. Blitz et al. conclude that, although these findings are important and relevant, they also highlight the fact that no significant reduction in car-use was observed. These findings have been elaborated upon in relation to the future design of interventions aimed at openness and a willingness to reduce car-use.

In their paper on dockless bikesharing systems, Chen et al. (Contribution 8) elaborate upon their influence on individuals' daily mobility patterns. They conclude that knowledge thus far is inadequate regarding the role of sociodemographics, social environments, travel attitudes and the built environment in the adoption and usage of dockless bikeshare 
systems. The aim of Chen et al. was to assess factors related to individuals' initial adoption and the frequency of use by the residents of Beijing. In their analysis of the survey data, they show that dockless bikeshare systems are more popular among younger, more highly educated, and median-income groups, but find no gender differences. They note that a greater number of roads in a neighborhood is related to greater odds of dockless bikesharing being adopted, but no such relationship was observed for the total length of bicycle lanes. Interestingly, having a pro-bicycle attitude played a strongly positive part in the initial use of the dockless bikeshare system, but became less important as regards frequency of usage. The authors conclude that, in analyzing the potential of dockless bikeshare adoption, it is relevant to acknowledge that bikesharing is not an isolated mode, but that it is closely connected with public transit. This relationship may be used to further promote the use of docked systems.

In the fourth paper, Mattsson et al. (Contribution 7) shift the focus to walking as an important transport mode in sustainable cities. They argue that, for people with impaired vision, the usability of pedestrian environments is highly affected after dark. Walking environments need to be carefully designed to provide opportunities for pedestrians to take relaxed walks without becoming exhausted, otherwise less sustainable alternatives may be preferred and chosen. In urban environments with many different types of pedestrians and road users, it is important for public lighting systems to support all users to the greatest degree possible. In their paper, Mattsson et al. present a usability study of a walkway in a city in southern Sweden. The intention of this study was to paint a broad picture of the visually impaired, and of how improved outdoor lighting relates to their perceptions and possibilities of moving around after dark. An intervention was applied involving the installation of new lighting systems using LED lights on a walkway. Interviews and observations involving visually impaired participants showed that this intervention generally improved the walkway's usability. Analyses of the observations indicated that the participants' ability to both orientate themselves and detect infrastructural elements increased, while the interviews showed an increase in the perceived quality of the walkway. So far, so good. However, the authors also note that the effects on the perceived level of comfort while walking were somewhat unclear, highlighting the need for caution and carefully evaluating new lighting systems to avoid creating designs that may ultimately restrict the visually impaired when walking after dark. The authors recognize that it is currently of great importance to acknowledge this as there is an ongoing large-scale transition to LED lighting in outdoor applications.

\subsection{Environmental Footprints of Daily Travel}

Although Cellina et al. (Contribution 2) estimated $\mathrm{CO}_{2}$ emissions and energy use in their GoEco! app, only one of the nine papers in this Special Issue had a specific focus on modelling environmental footprints and developing fine grained life-cycle assessments of daily travel. Sinha et al. (Contribution 4) start by arguing that it is commonly understood in sustainable transportation research that public transportation causes less environmental pressure than the car. However, is this really true? Sinha et al. aimed to develop a model for estimating potential environmental gains from changes in travel behavior. A passenger travel model was developed using the life-cycle inventories of different travel modes in order to calculate environmental footprints. When applied to a free public transport intervention, they found that the intervention was successful as it reduced car-use by $12 \%$. At the same time, however, the distance travelled increased substantially by bus, train, bicycle and on foot. Overall, the energy, carbon and nitrogen oxide footprints thus slightly increased after the intervention. By further modelling these findings, it was shown that if commuters were assumed to travel during peak hours, or numbers of public transport services were not affected by the increased numbers of commuters, then the overall environmental footprints would decrease. It was concluded that transport interventions are very complex. A car can, for instance, cause less environmental pressure when a public service vehicle (bus or train) runs at a lower rate of occupancy off-peak. 
Sinha et al. argue that this fact should be the basis for a more profound debate regarding public versus private transport. Interventions may result in the changes desired, but also in travel behavior increasing its overall impact. Taken together, these findings show that a very broad approach is necessary when planning and evaluating travel mode interventions.

\section{General Discussion}

Sinha et al. (Contribution 4) showed that a car travel mode generally causes a greater environmental footprint than public transport per passenger-kilometer, in a life-cycle perspective. Thus, understanding the car-user could help as regards motivating him/her to use public transport to a greater extent in order to achieve a more sustainable travel mode, especially when avoiding low occupancy hours. The meta-analysis by Olsson et al. (Contribution 1), aimed at understanding the car user's preferences and choices, indicated that car users are more inclined to think about prices, comfort, convenience, and an imagined sense of freedom. We therefore argue that public transport, or carpools, can offer the desired overall advantages if correct policy measures are introduced in order to increase relative performance and functionality. For example, reduced parking space availability [4,5], together with increased prices [6] for private cars [7], may connect with preferences and choices related to price, comfort, convenience, and freedom. At the same time, new policy initiatives can increase the performance and functionality of public or shared transport. Eventually, this may change attitudes towards public or shared transportation. However, the increased status of having a car, in addition to cultural values, may prevent changed attitudes [8].

Digitalization and artificial intelligence are essential and significant approaches to promoting public and shared transport [9-12], in order to shape sustainable transport. Two articles in this Special Issue, the GoEco! (Contribution 2) and the mobility service application for business travel (Contribution 5), showed a promising outcome of digitalization related to public- or shared transport. However, they faced technical (e.g., data collection, scalability, and security) and non-technical (e.g., business model) challenges [13,14]. In addition, the physical resources (i.e., material, energy, and emissions) required for digitalization must be considered jointly with the added benefit of the service [15]. Although digital aids can be an opportunity to facilitate the transition to sustainable travel, we still lack knowledge of how and when digitized processes could play a crucial role in sustainable travel. This is an area for further research. Hence, if digitalization and AI-supported systems are assumed to be essential in the future, then research could explore better/easier technologies (e.g., connected and autonomous vehicles, autonomous personal and unmanned aerial vehicles), various business models (e.g., mobility-as-a-service), and better information systems in order to enable sustainable transport.

Active travel (e.g., walking and cycling) supports a healthy lifestyle. It is an attractive travel mode and complements public transport [16]. Blitz et al. (Contribution 6) showed that infrastructure is important for increasing the intention to cycle and, perhaps most importantly, cycling more frequently. It is thus a measure that primarily strengthens the intention to cycle among those who already have a positive attitude towards cycling. However, streets favoring cyclists do not seem to affect the proportion of car journeys made. Thus, this infrastructure's ability to influence the transition to sustainable travel, at least in the short term, is probably limited. We conclude that attractive infrastructure needs to be supplemented with other measures that directly counteract car-use. Thus, the combination of different measures is still an area for experimentation and testing.

Sinha et al. (Contribution 4) argued that interventions and transport planning should consider taking a broader systems approach. Sectoral interventions are necessary in order to gain deep insight into specific challenges in different sectors. However, interventions may lead to positive (or negative) social impacts and economic outcomes, both in the studied sector and in other sectors. Therefore, we predict that the links between specific sector interventions and overall multisector impacts will become increasingly important to study and evaluate further. Which goals will have to be achieved in the transport sector 
specifically? Today, we are predominantly discussing multifactorial improvements in a general sense.

In our opinion, ongoing political discussions aimed at improving transport systems greatly underestimate the magnitude of the changes to the practical interventions that are needed to combat the existing climate crisis and the upcoming ecological crisis. In this sense, one could argue that the studies published in the Special Issue only scratch the surface as regards what we might need to do in the future, and in a broader sense. They all appear to expect developments to continue in more or less the same direction as today. We need to ask ourselves: Is our social compass pointing in the right direction? Here, social and psychological studies of opinions and attitudes concerning very different futures could be of great help. What if people in rich countries have to face a future with fewer resources and opportunities to consume than today? Which changes in preferences and attitudes might be foreseen in such studies?

Future studies should also focus more on reducing the communication gap between researchers and political leaders. Due to the foreseen, profound and necessary changes to the global carbon metabolism (climate change mitigation), the global transport system will have to change accordingly, since it is fueled almost entirely by fossil fuels. We do not visualize politicians seeing the same picture of the future that many researchers do and thus communication will have to increase. Politicians have no easy task navigating the research landscape while making informed decisions. As researchers, it is time for us to start looking in the mirror and asking ourselves if it really is the politicians we should blame. The question we should ask ourselves, perhaps, is instead how we, as researchers, can be better at helping politicians to make informed decisions in the interest of change. It is apparent that an increasing number of researchers, experts, and laymen are starting to feel that the climate crisis discussed at the recent COP26 meeting is turning into a real and serious development crisis. How do we meet these challenges as transport researchers? Interestingly, the communication gap between researchers and decisionmakers has changed profoundly in the light of the COVID-19 pandemic. Suddenly, the joint international goal of handling this virus crisis has led to close collaborations and a smaller gap between the different stakeholders. Competing research teams and companies all around the world are now rapidly sharing knowledge, leading to great progress. We should learn from this and see if similar processes can be implemented in relation to sustainable transportation and the potential climate crisis.

We believe that this Special Issue's contributions, and the discussion above, highlight a number of interesting and important findings. We also raises questions that need further attention in future research focusing on sustainable transport. Looking at our Figure 1, visualizing the dimension included in this issue, it is clear that the core has been personal travel, but also that other dimensions also exist that should be emphasized. Linking specific transport studies to a broader systems perspective, and to the overarching discussion of sustainability, will be a necessity if we want to gain a better understanding of the transport system as a whole. To succeed, this requires increased collaboration between many different actors; not only between different research domains, but also, as noted, involving decisionmakers and politicians. While achieving this, we must never forget that it is the citizens who use, and benefit from, the transport systems that should be front and center. In the end, as has been highlighted in this issue, the policies and interventions we choose to implement will have consequences for the individual. We thus need to evaluate and balance the benefits (e.g., increased health and wellbeing, better air quality, lower emissions, less congestion) against the potential costs (e.g., limiting autonomy, social exclusion, increased monetary costs, less convenience) for the actions we propose. Hence, although we agree that reducing the negative ecological impact is urgently needed, we must also acknowledge that social inclusion and wellbeing are important goals. 


\title{
4. List of Contributions
}

1. Olsson, L.E.; Maier, R.; Friman, M. Why Do They Ride with Others? Meta-Analysis of Factors Influencing Travelers to Carpool.

2. Cellina, F.; Bucher, D.; Mangili, F.; Simão, J.V.; Rudel, R.; Raubal, M. A Large Scale, App-Based Behaviour Change Experiment Persuading Sustainable Mobility Patterns: Methods, Results and Lessons Learnt.

3. Bergman, Z. Trains in the Land of the Car: A Case Study of Mobility as Agency in the United States.

4. Sinha, R.; Olsson, L.E.; Frostell, B. Sustainable Personal Transport Modes in a Life Cycle Perspective-Public or Private?

5. Andersson, A.; Hiselius, L.W.; Berg, J.; Forward, S.; Arnfalk, P. Evaluating a Mobility Service Application for Business Travel: Lessons Learnt from a Demonstration Project.

6. Blitz, A.; Busch-Geertsema, A.; Lanzendorf, M. More Cycling, Less Driving? Findings of a Cycle Street Intervention Study in the Rhine-Main Metropolitan Region, Germany.

7. Mattsson, P.; Johansson, M.; Almén, M.; Laike, T.; Marcheschi, E.; Ståhl, A. Improved Usability of Pedestrian Environments After Dark for People with Vision Impairment: an Intervention Study.

8. Chen, Z.; Van Lierop, D.; Ettema, D. Exploring Dockless Bikeshare Usage: A Case Study of Beijing, China.

9. Wikstrøm, R.D.; Böcker, L. Changing Suburban Daily Mobilities in Response to a Mobility Intervention: A Qualitative Investigation of an E-bike Trial.

\begin{abstract}
Author Contributions: Conceptualization, L.E.O., R.S. and B.F.; writing-original draft preparation, L.E.O., R.S., B.F. and M.F.; writing-review and editing, L.E.O., R.S., B.F. and M.F.; All authors have read and agreed to the published version of the editorial. All authors have read and agreed to the published version of the manuscript.

Funding: This research was funded by the Swedish Energy Agency (in Swedish, Energimyndigheten), grant number 43210-1 and 50504-1.

Conflicts of Interest: The authors declare no conflict of interest. The funders had no role in the design of the study; in the collection, analyses, or interpretation of data; in the writing of the editorial, or in the decision to publish the results.
\end{abstract}

\section{References}

1. UN Sustainability Goals. The 2030 Agenda for Sustainable Development. 2015. Available online: https://sdgs.un.org/goals (accessed on 25 November 2021).

2. EU. Sustainable Transport and Fuels. 2021. Available online: https://ec.europa.eu/jrc/en/research-topic/sustainable-transportand-fuels (accessed on 25 November 2021).

3. Olsson, L.E.; Huck, J.; Friman, M. Intention for car use reduction: Applying a stage-based model. Int. J. Environ. Res. Public Health 2018, 15, 216. [CrossRef] [PubMed]

4. Badland, H.M.; Garrett, N.; Schofield, G.M. How does car parking availability and public transport accessibility influence work-related travel behaviors? Sustainability 2010, 2, 576-590. [CrossRef]

5. De Gruyter, C.; Truong, L.T.; Taylor, E.J. Can high quality public transport support reduced car parking requirements for new residential apartments? J. Transp. Geogr. 2020, 82, 102627. [CrossRef]

6. Simićević, J.; Milosavljević, N.; Maletić, G.; Kaplanović, S. Defining parking price based on users' attitudes. Transp. Policy 2012, 23, 70-78. [CrossRef]

7. Marsden, G. The evidence base for parking policies-A review. Transp. Policy 2006, 13, 447-457. [CrossRef]

8. Linda, S. Can public transport compete with the private car? IATSS Res. 2003, 27, 27-35.

9. Leviäkangas, P. Digitalisation of Finland's transport sector. Technol. Soc. 2016, 47, 1-15. [CrossRef]

10. Canzler, W.; Knie, A. Mobility in the age of digital modernity: Why the private car is losing its significance, intermodal transport is winning and why digitalisation is the key. Appl. Mobilities 2016, 1, 56-67. [CrossRef]

11. Truong, T.M.T. Impacts of digitalisation on travel behaviour in Hanoi city centre. AIP Conf. Proc. 2021, $2428,040004$.

12. Cruz, C.O.; Sarmento, J.M. "Mobility as a service" platforms: A critical path towards increasing the sustainability of transportation systems. Sustainability 2020, 12, 6368. [CrossRef]

13. Davidsson, P.; Hajinasab, B.; Holmgren, J.; Jevinger, Å.; Persson, J.A. The fourth wave of digitalization and public transport: Opportunities and challenges. Sustainability 2016, 8, 1248. [CrossRef] 
14. Vinuesa, R.; Azizpour, H.; Leite, I.; Balaam, M.; Dignum, V.; Domisch, S.; Felländer, A.; Langhans, S.D.; Tegmark, M.; Nerini, F.F. The role of artificial intelligence in achieving the Sustainable Development Goals. Nat. Commun. 2020, 11, 1-10. [CrossRef] [PubMed]

15. Itten, R.; Hischier, R.; Andrae, A.S.; Bieser, J.C.; Cabernard, L.; Falke, A.; Ferreboeuf, H.; Hilty, L.M.; Keller, R.L.; Lees-Perasso, E. Digital transformation-Life cycle assessment of digital services, multifunctional devices and cloud computing. Int. J. Life Cycle Assess. 2020, 25, 2093-2098. [CrossRef]

16. Maltese, I.; Gatta, V.; Marcucci, E. Active Travel in Sustainable Urban Mobility Plans. An Italian overview. Res. Transp. Bus. Manag. 2021, 40, 100621. [CrossRef] 